\title{
Relationship between supramaximal flows and flow-limiting mechanisms
}

\author{
H. Sala*, F. Galindez*, A. Badolati*, D. Rodenstein**
}

\begin{abstract}
Relationship between supramaximal flows and flow-limiting mechanisms. H. Sala, F. Galindez, A. Badolati, D. Rodenstein. CERS Journals 1996.

ABSTRACT: The aim of this study was to evaluate the relationship between supramaximal flows (SF) and indices of airway mechanics.

We studied 26 asymptomatic young subjects ( 13 smokers, mean \pm sD $15.9 \pm 6.6$ packyears). Subjects performed maximal expiratory flow-volume (MEFV) curves, according to the American Thoracic Society (ATS) criteria, on a rolling-seal spirometer and then repeated them through a specially devised valve, which occluded the mouthpiece either 3 or 6 times $\mathrm{s}^{-1}$ with a ratio of open:closed time of 3:1. Envelope MEFV curves for 3 and $6 \mathrm{~Hz}$ occlusions were constructed passing through the SF obtained after each occlusion, and the increment in flow at $50 \%$ of vital capacity was measured with respect to the basal curve $\left(\Delta V^{\prime} \max 50\right)$.

We found that the $\Delta V^{\prime}$ max50 at 3 and $6 \mathrm{~Hz}$ correlated to the baseline forced midexpiratory flow (FEF25-75) in \% of predicted value ( $r=-0.73$ and $r=-0.55$, respectively).

Our results suggest that inhomogeneities within the lung are an important mechanism in the occurrence of supramaximal flow in normal subjects.

Eur Respir J., 1996, 9, 512-516.
\end{abstract}

*Hospital Nacional Alejandro Posadas, Haedo, Argentina. **Pneumology Unit, Cliniques Universitaires Saint Luc, Université Catholique de Louvain, Brussels, Belgium.

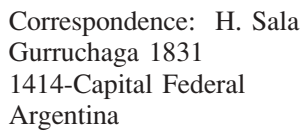

Keywords: Airway configuration forced expiration lung inhomogeneity pendelluft

Received: December 21994 Accepted after revision October 11995
Maximal expiratory flows are characterized by effort dependency, i.e. stronger efforts result in higher flows, at high lung volume and by effort independency at lower lung volumes [1]. Effort independency means that once a relatively modest effort is performed, flow levels reach a maximum that cannot be surpassed with further increase in effort and pleural pressure. The level where flow becomes maximal is determined by the mechanical properties of the lung, and is explained in terms of fluid mechanics by the choke-point theory [2].

When a maximal expiratory manoeuvre is initiated from a lung volume below total lung capacity (TLC), either voluntarily, during coughing or by the sudden opening of a valve, the resulting maximum expiratory flowvolume (MEFV) curve, termed partial MEFV curve, shows a discrepancy with regard to the complete MEFV curve (initiated from TLC) for matched lung volumes. The first part of the partial MEFV curve usually shows flows that are higher than maximum flows for that absolute lung volume on a complete MEFV curve. These flows, which are greater than "maximum" and, thus, termed supramaximal flows (SF) are transient. After a given volume has been exhaled, flows return to the maximum level obtained from a complete exhalation manoeuvre. Several factors may contribute to the SF. KNUDSON et al. [3] postulated that the transient flows exceeding the maximal flow represent volume displacement from the collapsing airway. PeDERSEN et al. [4] demonstrated, however, that SF cannot be completely explained by flow from the collapsing flow-limiting segment.
Preliminary data from our laboratory have suggested a relationship between SF and airflow limitation. The present study was undertaken to further clarify this matter.

\section{Materials and methods}

Twenty six young asymptomatic subjects, with no history of lung disease and with normal clinical and chest radiographic examination, were studied. Thirteen of the 26 subjects were smokers, with a mean \pm SD smoking history of $15.9 \pm 6.6$ packs-years. Five out of the 13 nonsmokers and 5 out of the 13 smokers were females. All subjects were hospital employees and the mean age for the whole group was $29 \pm 3$ yrs (range 22-34 yrs). Informed consent for the study was obtained from all subjects. This study was approved by the Ethics Committee of our institution.

Subjects performed baseline complete MEFV according to the American Thoracic Society (ATS) recommendations [5]. Once a reliable set of MEFV curves was obtained, the subjects repeated the manoeuvre exhaling from TLC to residual volume (RV) through a specially designed electromechanical valve (IEP, Claypole, Argentina), which allowed rapid (closing and opening time: $15 \mathrm{~ms}$ ) and complete interruption of flow at a rate of 3 or $6 \mathrm{~Hz}$. The ratio of open:closed time was 3:1. Each opening of the valve resulted in a transient SF when compared to the baseline maximum flow at matched lung volume (fig. 1). Since at $3 \mathrm{~Hz}$ only three interruptions 

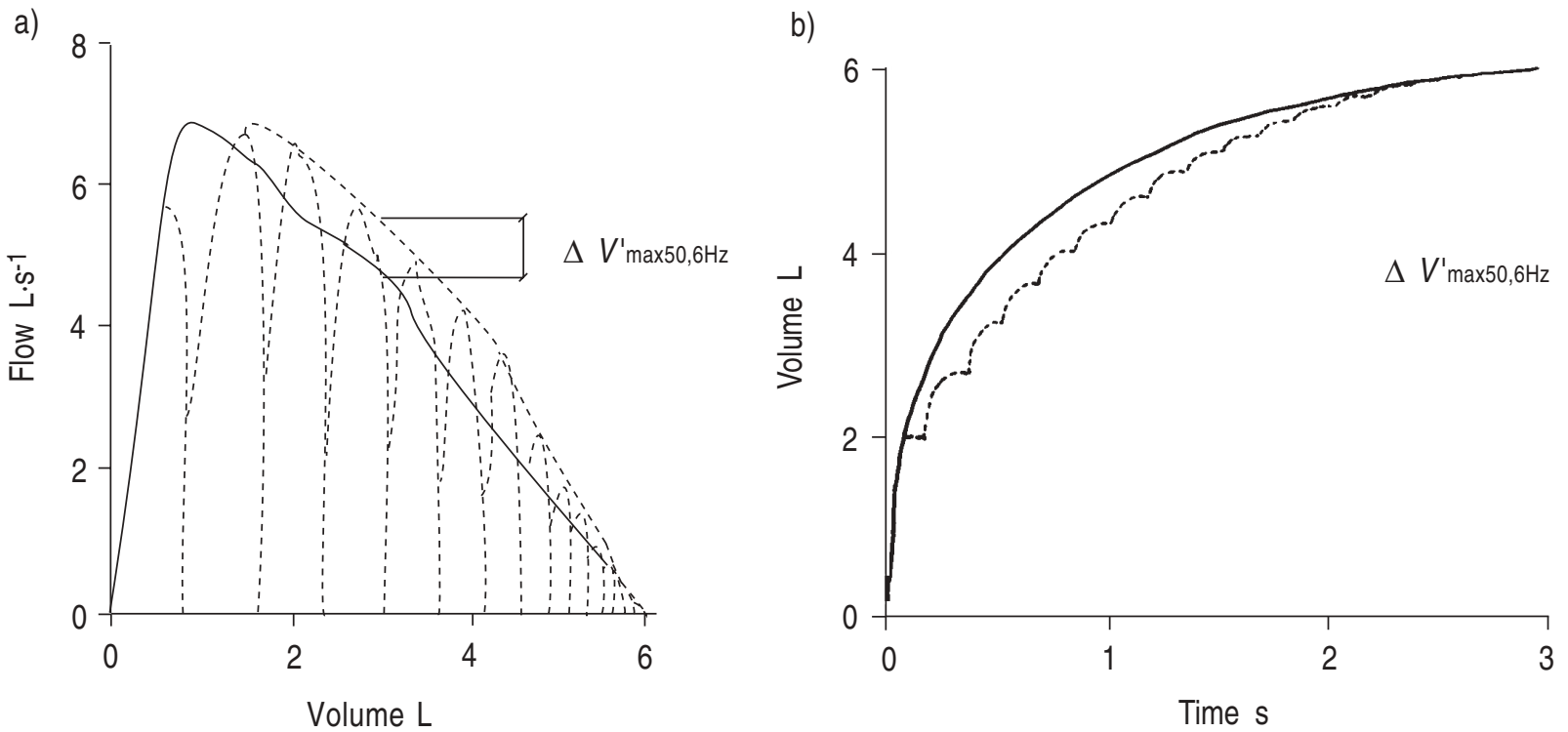

Fig. 1. - a) Basal (-) and $6 \mathrm{~Hz}$ (-- -) interrupted maximal expiratory flow-volume loop from from one asymptomatic subject. An envelope curve (dashed line) passing through the peaks of supramaximal flows was constructed. $\Delta V$ 'max50 was determined matching the curves at total lung capacity. b) Baseline (-) and $6 \mathrm{~Hz}$ ( -. - ) interrupted time-volume curve from the same subject. $\Delta V^{\prime}$ max 50 : difference in flow at $50 \%$ of vital capacity.

take place in the first second when normal subjects expire about $75 \%$ of their vital capacity, forced expiratory manoeuvres were repeated enough times to obtain a sufficient number of interruptions early in the forced expiratory manoeuvre. For $6 \mathrm{~Hz}$ interruptions, at least four MEFV curves were performed. The order of the runs was: firstly, baseline curves; followed by $3 \mathrm{~Hz}$ and then $6 \mathrm{~Hz}$ interrupted curves. Only curves differing by less than $5 \%$ of the forced expiratory capacity (FVC) with respect to the baseline FVC were accepted for analysis.

Measurements were performed without tubing between the mouth and the valve, and with stiff tubes between the valve and the spirometer. Interrupted curves were matched at TLC and an envelope curve passing through the peaks of SF was constructed. Three curves were obtained: the baseline curve; and the 3 and $6 \mathrm{~Hz}$ interrupted curves (fig. 1). The differences in flow at $50 \%$ of the baseline FVC were measured both for $3 \mathrm{~Hz}\left(\Delta V^{\prime} \max 50,3 \mathrm{~Hz}\right)$ and $6 \mathrm{~Hz}\left(\Delta V^{\prime} \max 50,6 \mathrm{~Hz}\right)$ curves. From baseline curves,

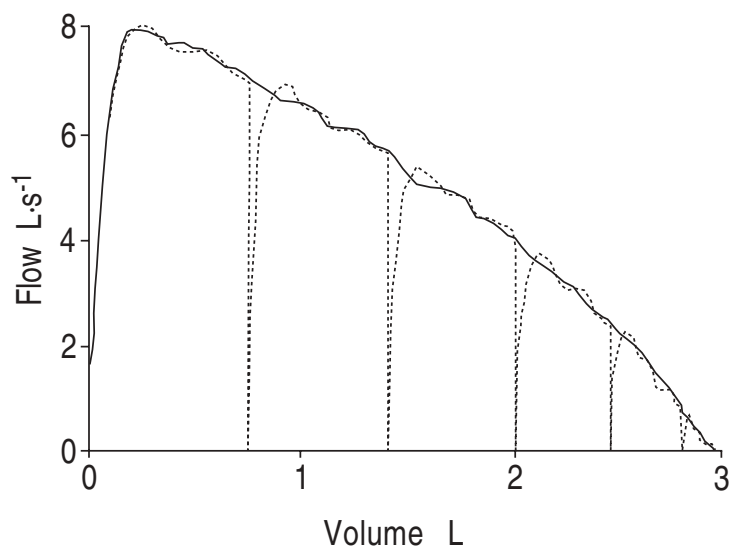

Fig. 2. - Basal (-) and $3 \mathrm{~Hz}(. . . .$.$) interrupted maximal expiratory$ flow-volume loop generated by explosive decompressor. the FVC, forced expiratory volume in one second (FEV1), forced mid-expiratory flow (FEF25-75) and $V^{\prime} \max 50$, were also measured.

All manoeuvres were performed using a rolling-seal spirometer (Sensormedics-USA), with a flat frequency response up to $7 \mathrm{~Hz}$ (manufacturer's unpublished data) with a resistance of less than $2 \mathrm{cmH}_{2} \mathrm{O} \cdot \mathrm{L} \cdot \mathrm{s}^{-1}$ at a flow of $12 \mathrm{~L} \cdot \mathrm{s}^{-1}$. The spirometer was coupled to an IBM XT compatible personal computer. Built as described, the equipment complied with current ATS recommendations [6]. The inertial characteristics of the spirometer were tested using an explosive decompressor (ATSOK, Buenos Aires, Argentina) [7]. The addition of the electromechanical valve to the circuit did not result in the appearance of SF in the curve obtained with the explosive decompressor, either at 3 or $6 \mathrm{~Hz}$ (fig. 2), for flows in the range of the $V^{\prime} \max 50$ of the subjects studied.

Table 1 - Anthropometric and spirometric data for all subjects

\begin{tabular}{lc}
\hline Age yrs & $29 \pm 3$ \\
Height cm & $173 \pm 9$ \\
FVC \% pred & $100 \pm 8$ \\
FEV $\%$ pred & $105 \pm 10$ \\
FEF25-75 \% pred & $108 \pm 24$ \\
$\Delta V^{\prime} \max 50,3 \mathrm{~Hz} \%$ & $25 \pm 19$ \\
$\Delta V^{\prime} \max 50,6 \mathrm{~Hz} \%$ & $15 \pm 17 *$ \\
$\Delta V^{\prime} \max 50,3 \mathrm{~Hz} \mathrm{~L} \cdot \mathrm{s}^{-1}$ & $1.19 \pm 0.87$ \\
$\Delta V^{\prime} \max 50,6 \mathrm{~Hz} \mathrm{~L} \cdot \mathrm{s}^{-1}$ & $0.70 \pm 0.82^{* *}$ \\
\hline
\end{tabular}

Values are expressed as mean \pm SD. FVC: forced vital capacity; FEV1: forced expiratory volume in one second; FEF25-75: forced mid-expiratory flow; $\Delta V^{\prime} \max 50,3 \mathrm{~Hz}$ and $\Delta V^{\prime} \max 50,6 \mathrm{~Hz}$ : increment in flow at $50 \%$ of vital capacity with respect to baseline, at 3 and $6 \mathrm{~Hz}$, respectively. $*^{*}$ p $<0.001$ between $\Delta V^{\prime} \max 50,3 \mathrm{~Hz}$ and $\Delta V^{\prime} \max 50,6 \mathrm{~Hz}$ in \% increase; ${ }^{* *}$ : $\mathrm{p}<0.02$ between $\Delta V^{\prime} \max 50,3 \mathrm{~Hz}$ and $\Delta V^{\prime} \max 50,6 \mathrm{~Hz}$ in absolute values. 
Table 2. - Results of six subjects who performed the manoeuvres with and without cheek and chin support

\begin{tabular}{lcc}
\hline $\begin{array}{l}\text { Subject } \\
\text { No. }\end{array}$ & $\Delta V^{\prime}$ max $50,6 \mathrm{~Hz}$ & $\begin{array}{c}\Delta V^{\prime} \max 50,6 \mathrm{~Hz} \\
\text { holding cheeks }\end{array}$ \\
\hline 1 & 17.3 & 17.1 \\
4 & 12.1 & 11.4 \\
9 & 3.4 & 3.1 \\
11 & 24.1 & 25.2 \\
18 & 17.9 & 18.0 \\
23 & 10.4 & 11.1 \\
\hline Mean & 14.2 & 13.9 \\
\pm SD & \pm 6.5 & \pm 7.1 \\
\hline
\end{tabular}

Results are expressed in $\%$ of baseline $\Delta V^{\prime} \max 50$. Differences are not significant for the group. $\Delta V^{\prime} \max 50$ : difference in flow at $50 \%$ of vital capacity; $\Delta V^{\prime} \max 50,6 \mathrm{~Hz}$; increment in flow at $50 \%$ of vital capacity with respect to baseline, at $6 \mathrm{~Hz}$.

Finally, to assess the influence of extrathoracic airways on the measurements, six subjects from the original 26 repeated the study whilst holding their cheeks and chin firmly with both hands. Comparison is made between $\Delta V^{\prime} \max 50,3 \mathrm{~Hz}$ and $\Delta V^{\prime} \max 50,6 \mathrm{~Hz}$, either expressed in absolute values or as a percentage of baseline $\Delta V^{\prime} \max 50$ (table 1$)$. Correlation between $\Delta V^{\prime} \max 50,3 \mathrm{~Hz}$ and $\Delta V^{\prime} \max 50,6 \mathrm{~Hz}$ and the baseline FEF25-75 expressed as a percentage of predicted values [8], was performed using linear regression analysis. For all statistical analysis, a p-value less than 0.05 was considered significant.

\section{Results}

Mean anthropometric and spirometric data are given in table $1 . \mathrm{SF}$ at $3 \mathrm{~Hz}$ were higher than those at $6 \mathrm{~Hz}$,

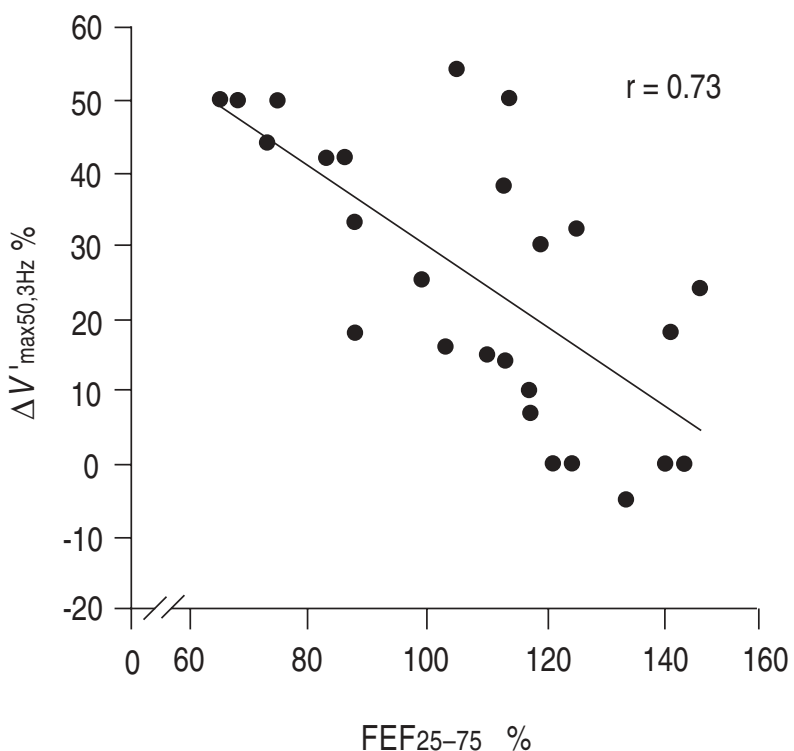

Fig. 3. - Negative correlation between $\mathrm{FEF}_{25-75}$ expressed in $\%$ of reference value and $\Delta V^{\prime}$ max $50,3 \mathrm{~Hz}$ expressed in $\%$ of increase with respect to baseline $V^{\prime} \max 50$. FEF25-75: forced mid-expiratory flow; $\Delta V^{\prime}$ max $50,3 \mathrm{~Hz}$ : increment in flow at $50 \%$ of vital capacity with respect to baseline, at $3 \mathrm{~Hz}$

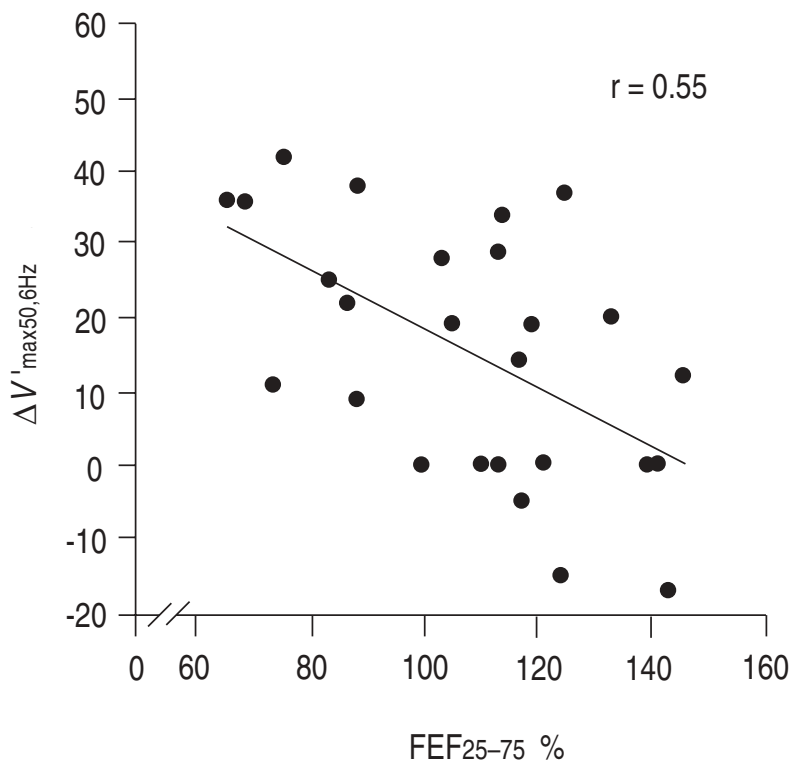

Fig. 4. - Negative correlation between FEF25-75 expressed in \% of reference value and $\Delta V^{\prime} \max 50,6 \mathrm{~Hz} . \quad \Delta V^{\prime} \max 50,6 \mathrm{~Hz}$ : increment in flow at $50 \%$ of vital capacity with respect to baseline, at $6 \mathrm{~Hz}$; FEF25-75: forced mid-expiratory flow.

both with results expressed as a percentage of increase with respect to baseline maximal flow or in absolute values $(\mathrm{p}<0.001$ and $\mathrm{p}<0.02$, respectively). Table 2 shows the results with and without cheek and chin support. No significant differences were noted.

$\Delta V$ 'max 50 both for 3 and $6 \mathrm{~Hz}$ interuptions correlated significantly with baseline FEF25-75 values (figs 3 and 4). No significant correlation was found between $\Delta V^{\prime} \max 50$ (at 3 or $6 \mathrm{~Hz}$ airway closure frequency), expressed in absolute values, and height $(\mathrm{r}=0.21 ; \mathrm{p}>0.05)$.

\section{Discussion}

The main finding of this study was that $\Delta V^{\prime} \max 50$ was related to FEF25-75 in the group of young subjects studied. Moreover, SF transients were higher for 3 than 6 interruptions $\cdot \mathrm{s}^{-1}$.

Before discussing our results, some methodological aspects must be considered. For fast expiration with high flows in young subjects, the inertial characteristic of the equipment is crucial. The addition of the electromechanical valve did not result in the appearance of SF transients in the flow-volume curve obtained using an explosive decompressor. This suggests that SF transients were not due to artifactual overshooting secondary to the inertial characteristics of the spirometer. Comparisons between the spirometer that we have used here with others based on a pneumotachograph demonstrated no significant differences in the measuring of the peak expiratory flow rate (PEFR), further confirming the adequate response of our rolling seal spirometer at high flows [6]. Because our discussion is based partly on the higher SF observed when flow was interrupted at 3 versus $6 \mathrm{~Hz}$, the second methodological point that must be considered is whether maximal flow can be achieved during the $125 \mathrm{~ms}$ that corresponds to the opening time at $6 \mathrm{~Hz}$. As can be seen 
in the flow-volume and in the volume-time curves of figure 1 , a decline in maximal flow is seen before the next interruption of flow occurs. This observation is reasonable because peak expiratory flow rate (PEFR) is achieved during the first $60 \mathrm{~ms}$ after the start of a maximal exhalation. Supramaximal flows have been attributed to the emptying of large airways by dynamic compression of the flow-limiting segment downstream of the choke-point [3]. In healthy subjects, at the beginning of the forced expiration, the choke-point is located in the trachea and moves peripherally as lung volume and recoil pressure decrease [9-11]. In children with cystic fibrosis, LANDAU et al. [12] found a direct relationship between the dead space measured with $\mathrm{N}_{2}$ wash-out and the volume of the transient SF. Nevertheless, PEDERSEN et al. [4], using a mechanical lung model and direct measurement of flow in open chest dogs, demonstrated that SF was greater than that from the collapsing airway. They suggested that SF are wave-speed flows determined by change in the airway configuration from an unstable configuration that leads to the PEFR to a more stable configuration permitting a smaller flow. The change in airway configuration noted by PEDERSEN et al. [4] was observed at a $15 \mathrm{~Hz}$ flow interruption rate, far in excess of the maximum of $6 \mathrm{~Hz}$ that we provoked.

We found no significant correlation between SF and height measured in absolute values. Inasmuch as anatomical dead space is related to height [13], this supports the idea that, at least in normal subjects, the dynamic compression of the large airways might not fully explain the SF.

Because changes in airway configuration are so fast, they probably cannot fully explain the observation that $\mathrm{SF}$ are higher at 3 than at $6 \mathrm{~Hz}$ interruption rate.

The difference that we observed between $\Delta V ' \max 50$ at 3 and $6 \mathrm{~Hz}$ is even more significant if the driving pressure is considered to be smaller after the interruption of the flow at 3 than at $6 \mathrm{~Hz}$ due to stress relaxation. D'ANGelo et al. [14] demonstrated that a breathhold immediately before a forced expiration induced a significant drop in maximal flow, and suggested that this was due to stress relaxation during breathhold time. Since closed time was longer during $3 \mathrm{~Hz}$ than during $6 \mathrm{~Hz}$ airway closure in our study, stress relaxation should have been more notable at $3 \mathrm{~Hz}$, leading to a lower $\Delta V^{\prime} \max 50$, but this is the converse of what was found; in fact, the higher SF observed at $3 \mathrm{~Hz}$ in comparison to $6 \mathrm{~Hz}$ is, in terms of stress relaxation, even more relevant.

The significant relationship observed between $\Delta V^{\prime} \max 50$ and indices of airway mechanics could be due to the upstream migration of the choke-point. This means that in subjects with airflow limitation the downstream flowlimiting segment has a larger volume which could produce higher SF. However, in our young subjects with normal or near normal maximal flows, it is unlikely that the choke-point migration might be of a magnitude large enough to explain this relationship. McNAmAra et al. [15] have demonstrated that healthy canine lungs empty heterogeneously with different regional choke-points. This observation was also supported by MeLissinos et al. [16], who showed that forced expiration even in asymptomatic smokers is not the result of uniform emptying of all the lung compartments. It appears, thus, that even in normal lungs inhomogeneities do exist in the mechanical characteristics of different lung units, with faster and slower units. This is not surprising, since it is known that the branching tree anatomy is characterized by irregular dichotomy, so that length and cross-sectional diameters of the bronchial generations are, in themselves, inhomogenous throughout the lung [17].

During a forced expiration, the fast units would contribute more at an early stage in the expiration, whereas slow compartments would contribute less initially and more later. This implies that at the start of each occlusion, fast units should be smaller than slow units, because fast units have already emptied more than slow units during the preceding exhalation. During the interrupted time, with no flow out of the system, slow units with large volume and, hence, higher elastic recoil pressure could empty into fast units with lower volume and lower elastic recoil pressure (pendelluft). When interruption stops, fast units could again increase their early contribution to flow, resulting in higher transient flows. The contribution of slower units is less initially, and will be arrested by the next interruption. The significant difference observed between $\Delta V^{\prime} \max 50,3 \mathrm{~Hz}$ and $\Delta V^{\prime} \max 50,6 \mathrm{~Hz}$ suggests that this mechanism may contribute to SF.

Indeed, at $3 \mathrm{~Hz}$ the closed time $(80 \mathrm{~ms})$ is twice the closed time at $6 \mathrm{~Hz}$, thus allowing twice the time for pendelluft to take place. The relationship that we found between FEF25-75 (\% of predicted value) and SF may also depend, at least partly, on nonuniform emptying of the lung. Nevertheless, we cannot exclude the possibility that an increased pleural pressure during the interruption time might cause a decreased alveolar volume (due to thoracic gas volume compression) and, when the airway is open, this volume would be explosively decompressed contributing to supramaximal flows. This can contribute to the differences observed between 3 and 6 $\mathrm{Hz}$ (indeed, the longer closed time at $3 \mathrm{~Hz}$ would allow for more thoracic gas volume compression) but does not explain the relationship between supramaximal flow and the FEF25-75.

In summary, during the interrupted time of forced expiration, at least three phenomena could occur in the bronchial tree and lungs: 1) refilling of the flow-limiting segment by air provided by the alveoli; 2) change in airway configuration that leads to a downstream displacement of the choke-point, allowing for an unstable new configuration until the choke-point is relocated peripherally; and 3) a refilling of fast alveolar units by air provided by alveolar units with longer time constants. All three phenomena can contribute to supramaximal flow. Our data suggest that changes in configuration and pendelluft increase their contribution as inhomogeneities become more marked. Pendelluft as a contributor to supramaximal flow might play a relevant role in situations such as cough and more studies on this point are needed.

\section{References}

1. Hyatt RE, Black LF. The flow-volume curve: a current perspective. Am Rev Respir Dis 1973; 107: 191-199. 
2. Dawson SV, Elliot EA. Wave-speed limitation on expiratory flow: a unifying concept. $J$ Appl Physiol: Respirat Environ Exercise Physiol 1977; 43: 498-515.

3. Knudson RJ, Mead J, Knudson DE. Contribution of airway collapse to supramaximal expiratory flows. $J$ Appl Physiol 1974; 36: 653-667.

4. Pedersen OF, Lyager S, Ingram RH Jr. Airway dynamics in transition between peak and maximal expiratory flow. J Appl Physiol 1985; 59: 1733-1745.

5. ATS. Standardization of spirometry. Am Rev Respir Dis 1987; 136: 1285-1298.

6. Gardner RM, Hankinson JL, West BJ. Evaluating commercially available spirometers. Am Rev Respir Dis 1980; 121: 73-82.

7. Petusevsky ML, Lyons LD, Smith AA, Epler GR, Gaensler EA. Calibration of time derivates of forced vital capacity by explosive decompression. Am Rev Respir Dis 1980; 121: 343-350.

8. Roca J, Sanchis J, Agusti Vidal A. Spirometric reference values for a Mediterranean population. Bull Eur Physiopathol Respir 1982; 18: 101-102.

9. Mead J. Respiratory flow limitation: a physiologist's point of view. Fed Proc 1980; 39: 2771-2775.

10. Mead J, Turner JM, Macklem PT, Little JB. Significance of the relationship between lung recoil and maximum expiratory flow. J Appl Physiol 1967; 22: 95-108.
11. Wilson TA, Hyatt RE. Forced expiration. In: The lung: Scientific Considerations. Crystal RG, West JB, et al. eds. New York, Raven Press, 1991, pp 1021-1030.

12. Landau LI, Taussig LM, Macklem PT, Beaudry PH. Contribution of inhomogeneity of lung units to the maximal expiratory flow-volume curve in children with asthma and cystic fibrosis. Am Rev Respir Dis 1975, 111: 725-731.

13. Osmanlier D, Bowley N, Hunter DM, Pride NB. Relation between tracheal size and forced expiratory volume in one second in young men. Am Rev Respir Dis 1985, 132: 784-787.

14. D'Angelo E, Prandi E, Milic-Emili J. Dependence of maximal flow-volume curves on time course of preceeding inspiration. Am Rev Respir Dis 1992; 145(4): A28.

15. Mc Namara JJ, Castile RG, Glass GM, Fredberg JJ. Heterogeneous lung emptying during forced expiration. J Appl Physiol 1987; 63: 1648-1657.

16. Melissinos CG, Webster P, Tien YK, Mead J. Time dependence of maximum flow as an index of nonuniform emptying. J Appl Physiol: Respirat Environ Exercise Physiol 1979; 47: 1043-1050.

17. Weibel ER. Design of airway and blood vessels considered as branching trees. In: The Lung: Crystal RG, West JB, et al., eds. Scientific Considerations. New York, Raven Press, 1991, pp. 711-720. 